\title{
INFLUÊNCIA DO MOMENTO DA CHUVA NA EFICÁCIA DO HERBICIDA GLIFOSATE, EM DIFERENTES CONCENTRAÇÕES, NO INVERNO E NO VERÃO
}

\author{
Aimar F. F. Pedrinho Júnior ${ }^{1}$, Guilherme V. Felici ${ }^{2}$, Fausto M. Piva ${ }^{2}$, Gustavo Martini ${ }^{1}$, \\ Julio C. Durigan ${ }^{3}$. \\ ${ }^{1}$ Eng. Agrônomo, Mestrando em Agronomia pela FCAV/UNESP - Jaboticabal, SP. CEP-14870-000 \\ ${ }^{2}$ Graduandos em Agronomia. FCAV/UNESP - Jaboticabal, SP. Rod. Prof. Paulo D. Castellane, km 5. \\ ${ }^{3}$ Prof. Titular do Depto. de Fitossanidade, FCAV/UNESP- Jaboticabal, SP. \\ jcdurigan@fcav.unesp.br
}

\section{RESUMO}

Com o objetivo de estudar a influência da chuva sobre a eficácia de diferentes concentrações do herbicida glifosate em duas épocas do ano foram instalados dois experimentos. O de inverno foi realizado no período de julho a agosto de 2000 e o de verão, de janeiro a março de 2001. Utilizou-se o delineamento experimental de blocos ao acaso, com quatro repetições, com os tratamentos dispostos em esquema fatorial $\left(4 X X^{5}\right)+1$, sendo constituído por quatro concentrações de glifosate SAqC (360 g.L. $\mathrm{L}^{-1}$ de eq. ac.) $(0,5$; 1,$0 ; 2,0$ e 4,0\%) na calda de pulverização, correspondendo as doses crescentes de 360, 720, 1440 e 2880 g.ha de eq.ac., cinco intervalos sem chuva após a aplicação. (1, 2, 4, 6 e > 48 horas) e uma testemunha sem herbicida. A unidade experimental foi constituída por uma parcela 3,0 X 3,5 no inverno e 3,0 X 4,0 metros no verão. Os tratamentos foram aplicados em pós-emergência das plantas daninhas, utilizando-se um pulverizador costal, à pressão constante (mantida por ar comprimido) de $30 \mathrm{lbf} / \mathrm{pol}^{2}$, munido de barra com seis bicos DG 11002 , espaçados de $0,5 \mathrm{~m}$. Tanto no inverno como no verão foi simulada uma chuva de aproximadamente $20 \mathrm{~mm}$ em 60 minutos com o auxílio de um sistema de irrigação por aspersão. Nas duas épocas, a ocorrência da chuva foi prejudicial à ação do glifosate, principalmente nos menores intervalos sem chuva após a aplicação. Para proporcionar controle semelhante ao tratamento com intervalo de 48 horas sem chuva após a aplicação, no inverno, a concentração do herbicida na calda de 2,0\% v/v (1440 g. ha ${ }^{-1}$ de eq. ac. de glifosate) exigiu intervalo de pelo menos duas horas sem chuva após a aplicação. No verão, para alcançar o mesmo nível de controle foi necessário um período de pelo menos uma hora sem chuva após a aplicação, para a mesma dose de glifosate, e com a concentração do herbicida na calda de $1 \% \mathrm{v} / \mathrm{v}$ (720 g. ha ${ }^{-1}$ de eq. ac. de glifosate) obteve-se resultado satisfatório com período superior a duas horas sem chuva após a aplicação.

PALAVRAS-CHAVE: Controle de plantas daninhas, dessecação, concentração.

\begin{abstract}
Two field assays were carried out aiming to evaluate the rain effects on the glyphosate herbicide activity, applied at different concentrations, under two growing seasons (winter and summer). The experiments were conducted at the FCAV / UNESP Experimental Station, during 2000/01. The winter experiment was installed from June to August of 2000 and the summer one was installed from January to March of 2001. The treatments were glyphosate $(0,5 ; 1,0 ; 2,0$ e $4,0 \%)$, used as check treatment. In the field, all
\end{abstract}


the trials were set up in the randomized block experimental design, with four replications. The experimental plots was $3.0 \mathrm{~m}$ wide $\times 3.5 \mathrm{~m}$ long in the winter assays. In the summer one, the plots' size was $3.0 \mathrm{~m} \times 4.0 \mathrm{~m}$. The treatments were arranged in factorial designs $5 \mathrm{x}$ 4 factors, with five periods between the herbicide spraying and the rain incidence and four concentrations. The herbicide treatments were applied through a back spraying, with six nozzles DG 11002 spaced by $0.5 \mathrm{~m}$, at 30 p.s.i. constant pressions. The artificial rain was provided by a top irrigation system raining $18-19 \mathrm{~mm}$ during one hour. The artificial rain reduced the glyphosate action, mainly in the shorter periods. Raising the glyphosate concentration to $2.0 \%$ supressed the problems promoted by the rain, one hour after sprayings, under winter conditions. Similar results were observed raising the glyphosate concentration to $1.0 \%$, under summer conditions.

KEY WORDS: Weed control, winter and summer, rainfastness.

\section{INTRODUÇÃO}

O glifosate é uma das moléculas herbicidas mais utilizadas no Brasil, devido ao seu preço e à sua eficácia para grande número de espécies de plantas daninhas. Um fator muito importante que alavancou o consumo de glifosate no país foi o aumento das áreas de plantio direto, nas quais este herbicida é utilizado como dessecante. O seu consumo não é maior devido a não seletividade às plantas anuais cultivadas, limitando a sua utilização em pós-emergência das culturas convencionais ou não transgênicas.

$\mathrm{O}$ glifosate transloca-se nas plantas, levando à morte do sistema radicular e de estruturas reprodutivas de plantas perenes, como rizomas, bulbos e tubérculos. Possui um coeficiente de partição octanol/água extremamente baixo $(-4,1)$, indicando que a molécula tem baixa afinidade por substâncias graxas e altíssima por água. Esta é uma das causas principais de sua absorção relativamente lenta, tornando a aplicação arriscada em épocas chuvosas e obrigando o fabricante a recomendar período sem chuvas de 6 horas após a aplicação (KRUSE et al., 2000).

A ocorrência de chuva após a aplicação, principalmente de herbicidas inibidores de EPSPs, tem se mostrado um grande problema para os agricultores que necessitam fazer manejo de plantas daninhas em épocas chuvosas (PEDRINHO JUNIOR, 2001). JAKELAITIS et al, (2001) observaram que a chuva simulada uma hora após a aplicação anulou o efeito herbicida das formulações glifosate WG, CS, Transorb, Zapp e Zapp QI, no controle de Digitaria horizontalis. Estes ainda observaram uma diferenciação no controle de $D$. horizontalis quando a chuva foi simulada em períodos superiores a duas horas após a aplicação, mostrando as formulações Transorb, Zapp e Zapp QI melhor performance nesta situação. PEDRINHO JUNIOR et al (2002a) também notaram acentuada diferença entre formulações de herbicidas inibidores de EPSPs no controle de uma população daninha quando simulou-se chuva até quatro horas após a aplicação, tendo a formulação glifosate WG o pior desempenho em relação a glifosate CS, Transorb e Zapp. Resultados semelhantes foram observados por ROMAN (2001), que descreveu pior desenpenho da formulação glifosate WG, quando simulou-se chuva até quatro horas após a aplicação, para o controle de Brachiaria plantaginea, comparado aos resultados obtidos por glifosate Transorb e glifosate potássico.

DEUBER (1982) cita estudos mostrando que a absorção dos herbicidas é limitada pela quantidade que atravessa a cutícula da folha e esta é influenciada pelas condições ambientais onde a planta daninha está se desenvolvendo e pelas características do herbicida. Segundo TUCKER et al. (1994), o imazapyr é mais absorvido e translocado em 
Alternanthera philoxeroides do que o glifosate, devido a sua maior afinidade com os constituintes da cutícula da planta. Tentando aumentar a absorção de glifosate pelas plantas daninhas e minimizar os efeitos da chuva após a aplicação PEDRINHO JUNIOR et al (2002b) estudaram a adição de adjuvantes a calda, e observaram que a utilização de uréia (50g/L de calda), sulfato de amônio ( $100 \mathrm{~g} / \mathrm{L}$ de calda) e óleo vegetal (100ml/L de calda), não beneficiou a performance do herbicida glifosate no controle das plantas daninhas no inverno; e que a adição de uréia $(50 \mathrm{~g} / \mathrm{L}$ de calda) pode ser uma boa alternativa para o controle de plantas daninhas, no verão, em situações sujeitas à chuva até duas horas após a aplicação.

Outros fatores ambientais também influenciam na eficácia dos herbicidas no controle de plantas daninhas, como a temperatura, a luminosidade, a umidade do solo, a umidade relativa do ar e a geada (BAIRD, 1971; FAWCETT \& DAVIS, 1976; FERNANDEZ, 1979).

PEDRINHO JUNIOR (2001) observou diferenças consideráveis no controle de plantas daninhas no inverno e no verão. Ele relata que estas diferenças provavelmente tenham ocorrido devido a maior atividade metabólica das plantas durante o verão, com temperatura média acima de $25^{\circ} \mathrm{C}$, quando os sintomas e graus de fitointoxicação apareceram mais rapidamente e como conseqüência, nesta época o controle foi mais eficiente. Durante o inverno, provavelmente a ocorrência de temperaturas inferiores a $18^{\circ} \mathrm{C}$, minimizaram o metabolismo das plantas e como consequiência a absorção e translocação do herbicida dentro destas, reduzindo a inibição da síntese de aminoácidos aromáticos e assim o controle das plantas durante o inverno.

Estudos são realizados para que as recomendações garantam maior segurança ao agricultor na utilização deste herbicida, mesmo em época chuvosa. A reaplicação é uma prática que onera os custos de produção, demanda mais tempo de trabalho e aumenta a poluição ambiental. Além de que os efeitos podem ser prejudicados pelo estresse das plantas, ocasionados pela primeira aplicação.

O presente trabalho teve por objetivo estudar a influência da chuva, em diferentes períodos após a aplicação, na eficácia do herbicida glifosate em diferentes concentrações, em duas épocas do ano.

\section{MATERIAL E MÉTODOS}

Os experimentos foram realizados em condições de campo na Fazenda Experimental de Ensino e Pesquisa da Faculdade de Ciências Agrárias e Veterinárias UNESP, Campus de Jaboticabal-SP.

O experimento foi repetido em dois períodos do ano, sendo, no inverno e no verão. O clima da região, segundo a classificação de Koppen é do tipo Cwa, ou seja, mesotérmico de inverno seco, com temperatura média do mês mais quente, superior a $22{ }^{\circ} \mathrm{C}$, e do mês mais frio, a $18^{\circ} \mathrm{C}$. A cidade de Jaboticabal acha-se localizada na Latitude $21^{\circ} 15^{\prime} 22^{\prime \prime}$ e na Longitude $48^{\circ} 18^{\prime} 58^{\prime \prime}$, com altitude de 580 metros acima do nível do mar. O solo do local foi classificado, segundo CENTURION (1998), como sendo Latossolo Vermelho-Escuro, eutrófico, horizonte A moderado, textura muito argilosa e relevo suavemente ondulado.

Utilizou-se o delineamento experimental de blocos ao acaso, com quatro repetições, com os tratamentos dispostos em esquema fatorial $(4 \mathrm{X} 5)+1$, sendo constituído por quatro concentrações de glifosate SAqC (Roundup SA) (360 g. $\mathrm{L}^{-1}$ de eq. ac.) $(0,5 ; 1,0 ; 2,0$ e 4,0 $\%)$ na calda de pulverização, correspondendo as doses crescentes de 360, 720, 1440 e 2880 g. ha ${ }^{1}$ eq. ac., cinco intervalos sem chuva após a aplicação $(1,2,4,6$ e 48 h) e uma testemunha sem herbicida. Para maior facilidade de visualização, os tratamentos são 
apresentados na Tabela 1. A unidade experimental foi constituída por uma parcela de $3,0 \mathrm{x}$ $3,5 \mathrm{~m}$ no inverno e 3,0 x 4,0 m no verão.

O herbicida foi aplicado em pós-emergência das plantas daninhas, utilizando-se de um pulverizador costal manual, à pressão constante (mantida por ar comprimido) de 30 $\mathrm{lbf} / \mathrm{pol}^{2}$, munido de barra com seis bicos DG 11002, espaçados de 0,50 m.

$\mathrm{Na}$ Tabela 02, são apresentadas as plantas daninhas predominantes, comprimento e intensidade de infestação (cobertura da área) em cada um dos experimentos nas duas épocas do ano. Os dados referentes às condições climáticas, nos diferentes horários de aplicação e épocas do ano, para cada experimento, são apresentados na Tabela 03.

Nos dois experimentos, a simulação da chuva foi feita com o auxílio de um sistema de irrigação por aspersão, e a quantidade foi de aproximadamente $20 \mathrm{~mm}$ durante 60 minutos de irrigação, molhando todas as parcelas de uma só vez.

Os diferentes intervalos sem chuva após a aplicação foram conseguidos antecipando-se em seis, quatro, duas e uma hora da simulação da chuva. O período de 48 horas sem chuva foi conseguido realizando-se a aplicação do herbicida, em seus respectivos tratamentos, uma hora após o final da simulação da chuva, quando as plantas apresentavam as lâminas foliares totalmente secas.

Foram realizadas avaliações visuais de eficiência de controle aos 17, 26, 33 e 41 dias após a aplicação (DAA), no inverno, e aos 7, 14, 21 e 33 DAA, no verão. Foram atribuídas visualmente, as porcentagens de controle para as duas principais espécies de plantas daninhas segundo o método da EWRC (1968), onde controle total $=100 \%$ e nenhum controle $=0 \%$. Também foram quantificadas a matéria verde e seca das plantas recém colhidas aos 41 DAA (inverno) e 35 DAA (verão). Para isso, as plantas foram cortadas rente ao solo, em cada parcela, utilizando-se um quadrado para amostragem de 0,75 X 0,75 m. Logo após a coleta, pesou-se o material no local, para obter a matéria verde. Já a matéria seca foi obtida após secagem em estufa de circulação forçada à $65^{\circ} \mathrm{C}$, onde permaneceu por quatro dias.

Os dados foram submetidos à análise de variância, as quais foram realizadas com o auxílio do programa ESTAT, sendo as porcentagens transformadas em arco sen $\sqrt{\%}$.

\section{RESULTADOS E DISCUSSÃO}

No inverno, as maiores concentrações do herbicida proporcionaram resultados satisfatórios logo nas primeiras avaliações. Na Tabela 4, constata-se que aos 17 DAA a dose de 2880 (g.ha ${ }^{-1}$ de eq. ac) já mostrava um bom controle. Também pode-se observar o efeito negativo da ocorrência da chuva principalmente nos menores intervalos após a aplicação, na performance do herbicida.

Os aumentos das doses para 1440 e 2880 (g.ha ${ }^{-1}$ de eq. ac) compensaram, em parte, a redução na velocidade de ação que é característica no inverno, em função da menor atividade metabólica das plantas, proporcionando assim, resultado satisfatório nesta primeira avaliação. RODRIGUES (1994), afirma que o glifosate é um produto vulnerável à chuva, quando esta ocorre antes dele ser absorvido integralmente pela planta, ou seja, ter passado pela fase ativa da absorção. Quando o herbicida encontra-se dentro da folha, porém na primeira fase do período de absorção (fase passiva) ele pode, por diferença de concentração, sair da cutícula foliar para o meio externo. Possivelmente, com o aumento da concentração do herbicida na calda aumentou-se a possibilidade de absorção, incrementando a quantidade do produto químico em ambas as fases do processo.

Nas Tabelas 5, 6 e 7 tem-se o desdobramento das interações aos 26, 33 e 41 DAA. O resultado obtido $(96,5 \%)$ com a dose de 2880 (g.ha ${ }^{-1}$ de eq. ac), no tratamento que recebeu 
chuva simulada 1hora após a aplicação, mostra que o aumento da concentração do herbicida pode minimizar o efeito negativo promovido pela chuva. Ao comparar o controle obtido por todas as concentrações em todos os períodos de chuva simulada, constata-se que houve um incremento no controle das doses crescentes. Observa-se ainda, que o aumento na dose, principalmente para a concentração de 2 e $4 \%$, melhorou a velocidade de ação do herbicida no inverno. Esses resultados estão de acordo com BRYSON (1988) que observou o glifosate necessitar de um período sem chuva após a aplicação de 4 horas, para que não haja redução da sua eficácia. Segundo o autor o período sem chuva exigido após a aplicação é inversamente proporcional à dose do herbicida aplicado. No entanto os efeitos da interação de doses do herbicida com intervalos de ocorrência de chuva são afetados por diversos fatores, como: intensidade e freqüência da chuva, da espécie, do estado nutricional da planta, da atividade metabólica da planta, entre outros.

Diferentes dosagens de glifosate para o controle do capim-andropogo (Andropogon gayanus) foram testadas por BARROS \& SCALÉA (2000) e obtiveram os melhores resultados com o incremento da concentração do produto na calda. No entanto SOUZA et al (2000) não constataram diferenças significativas no aumento da concentração de glifosate e sulfosate na calda quando testaram a eficácia destes herbicidas na dessecação de milheto (Pennisetum typhoydes), capim-marmelada (Brachiaria plantaginea) e aveia preta (Avena strigosa). MCWHORTER \& HANKS (1993) também não encontraram diferença significativa com o aumento do volume de calda aplicado no controle de Soghum halepense, quando fixaram as dosagens de fenoxaprop, fluazifop, haloxyfop e quizalofop a $0,14 \mathrm{~kg} / \mathrm{ha}$ e sethoxydim a $0,28 \mathrm{~kg} / \mathrm{ha}$. BARROS (1995) não obteve diferença significativa com o aumento das doses de glifosate e sulfosate no controle de Brachiaria decumbens, o mesmo relata que possivelmente seja devido as doses elevadas que foram utilizadas, sem diferenças de controle entre a maior e a menor.

Duas horas sem chuva após a aplicação nas doses de 1440 e 2880 (g.ha ${ }^{-1}$ de eq. ac.) foram suficientes para proporcionar resultados finais de $93,7 \%$ e $98 \%$, respectivamente. O mesmo não ocorreu com as doses de 360 e 720 (g.ha ${ }^{-1}$ de eq. ac.), pois os resultados aos 41 DAA, eram de $20,0 \%$ e $43,7 \%$ de controle, respectivamente. Percebe-se que existe estreita relação entre o aumento da dose e o menor efeito da lavagem pela chuva, garantindo-se a absorção mínima necessária do herbicida para um resultado final adequado. No experimento ora mencionado, este diferencial de ação final é constatado com o aumento da concentração de $1 \%$ para $2 \%$. Até no período de 6 horas sem chuva após a aplicação, os percentuais de controle foram significativamente reduzidos para as concentrações de $0,5 \%$ $(25,0 \%)$ e $1,0 \%$ (77,5\%), em comparação com as maiores $2,0 \%(95,7 \%)$ e $4,0 \%(98,0 \%)$ na avaliação feita aos 41 DAA.

Para esta época do ano, a concentração mínima de 2,0\% (1440 g.ha ${ }^{-1}$ de eq. ac.) é necessária para suprir as diferenças de absorção pela planta, em função do seu próprio metabolismo e da lavagem pela chuva em períodos de uma ou duas horas após a aplicação.

Pode-se então, considerar-se a hipótese de recomendação da concentração mínima de $2 \%$ (1440 g.ha ${ }^{-1}$ de eq. ac.) de glifosate, para o controle de plantas daninhas, no inverno, sobretudo quando existe a possibilidade de ocorrência de chuvas após a aplicação, mesmo que em períodos mais quentes a dose exigida seja menor, para controle adequado. A temperatura e a chuva após a aplicação juntamente com a idade da planta e seu estado fisiológico e nutricional são importantes fatores que influenciam a absorção e translocação dos herbicidas (CAMARGO, 1977).

Os resultados do teste $\mathrm{F}$ aplicado às médias das porcentagens de controle geral das plantas daninhas, influenciados pela ocorrência de chuva simulada após a aplicação de 
diferentes concentrações de glifosate $\mathrm{SAqC}$, no verão, são apresentados na Tabela 8 . Observa-se que, apenas aos 7 DAA não ocorreu interação significativa entre concentração e intervalos após a aplicação, sendo essas médias submetidas ao teste de Tukey. Observa-se diferença de controle entre as concentrações, evidenciando também o efeito negativo da ocorrência da chuva após a aplicação. O controle é maior nos tratamentos onde foram aplicadas as maiores concentrações, $2 \%(36,5)$ e $4 \%(39,7)$ e nos maiores intervalos sem chuva após a aplicação.

Nas Tabelas 09, 10 e 11, são apresentados os desdobramentos das interações significativas aos 14, 21 e 33 DAA, respectivamente. O controle (93,7\%), obtido aos 14 DAA, com a maior concentração do herbicida, com o intervalo sem chuva de 1 hora após a aplicação, pode ser considerado muito bom, demonstrando que o aumento da dose (concentração) reduziu o efeito negativo negativo da ocorrência da chuva na eficácia do glifosate SAqC.

Ao fixar os menores intervalos de chuva após a aplicação, para a comparação da atividade das diferentes concentrações testadas, observa-se que, no verão uma menor concentração $1,0 \%$ (720 g.ha ${ }^{-1}$ de eq. ac.) é exigida, para demonstrar controle adequado.

Desta forma constata-se que no período "quente" a ação do herbicida é mais precoce devido ao metabolismo intenso das plantas, com conseqüente aumento da absorção.

$\mathrm{Na}$ Tabela 12 encontram-se as médias da matéria verde e seca aos 41 DAA (inverno) e 35 DAA (verão), respectivamente. Observa-se que a matéria verde acumulada no inverno difere estatisticamente entre os períodos sem chuva após a aplicação, sendo menor no intervalo de 48 horas sem chuva após a aplicação. Não ocorrendo diferença estatística no verão, indicando que a ação do produto no inverno é mais lenta e menor do que no verão.

Em temperaturas mais baixas, o metabolismo das plantas é mais lento, prejudicando a absorção do herbicida e acentuando a ação da chuva, na lavagem do produto depositado sobre a superfície foliar, que ainda não passou a cutícula. Com o aumento da concentração (dose) do glifosate, a quantidade do herbicida que penetra na planta, antes da ação da chuva, é suficiente para proporcionar maior controle.

O processo de absorção de um íon ou molécula ocorre integralmente quando da sua entrada no simplasto das células da epiderme foliar (DURIGAN ,1993), passando por duas fases distintas, uma passiva e outra ativa. Na primeira há a sua movimentação desde a superfície do vegetal até o lado externo da plasmalema preenchendo a região denominada ELA (Espaço Livre Aparente) que perfaz cerca de $20 \%$ do volume das células acessíveis a íons ou moléculas. $\mathrm{Na}$ fase ativa, eles atravessam a plasmalema para o interior do simplasto, necessitando de energia metabólica, influenciada pela temperatura e de forma irreverssível. ambas as fazes são influenciadas de forma positiva pelo aumento do gradiente de concentração entre o seu início e o final, sobretudo a positiva. Da mesma forma, a maior atividade metabólica da planta faz com que maior quantidade deles atravessem a membrana semi-permeável que é a plasmalema.

Face ao exposto, é possível entender porque concentrações iguais ou inferiores a $2,0 \%$ garantem resultados iguais aos proporcionados pela metade dela, no controle químico com glifosate de determinada comunidade infestante. da mesma forma, entende-se porque a chuva simulada após a aplicação afeta menos no período "quente" que no "frio" e porque os resultados aparecem mais rapidamente na primeira época.

No inverno para a obtenção de $98 \%$ de controle geral da comunidade infestante, foi necessária a utilização de 4,0\% (2880 g.ha-1 de eq. ac.) do produto comercial na calda, com intervalo de 1 hora sem chuva após a aplicação, aos 41 DAA. Já no verão, nesta mesma dose e para o mesmo nível de controle, foram necessários 21 dias. Para este mesmo 
intervalo sem chuva e na concentração de $1,0 \%$ (720 g.ha ${ }^{-1}$ de eq. ac.), os resultados de controle foram de $35 \%$ e $92 \%$, respectivamente para os períodos de inverno e verão, aos 33 DAA. No entanto, ao dobrar-se a concentração no inverno, o percentual de controle foi de $88,7 \%$.

\section{BIBLIOGRAFIA CITATA}

BAIRD, D.D.; UPCHURCH, R.P.; HOMESLEY, W.B.; FRANZ, J.E.. Introduction of a new broad spectrum postemergent herbicide class with utility for herbaceous perennial weed control. Proc. N. Cent. Weed Contr. Conf. 26 : 64-68, 1971.

BARROS, A.C. Evaluation of biological efficiency of the herbicide sulfosate, compared to glyphosate the desiccation of Brachiaria decumbens. Zeneca Agrícola,v.2 p.43-44, 1995.

BARROS, A. C. \& SCALÉA, M. J. Eficiência biológica de glyphosate no controle (dessecação) do capim-andropogo. Revista Brasileira de Herbicidas. v.1.n.1, p.61-65, 2000.

BRYSON, C.T. Effects or rainfall on foliar herbicides applied to seedling johnsongrass (Sorghum halepense) Weed Technology, v.2,. p. 124-130, 1988.

CAMARGO, P.N. Interações herbicidas - planta. Piracicaba, Apostila (mimeografada). ESALQ, 78p. 1977.

CENTURION, J.F. Caracterização e classificação dos solos da Faculdade de Ciências Agrárias e Veterinárias de Jaboticabal. 1998. 84f. Tese (Livre Docência) Faculdade de Ciências Agrárias e Veterinárias, Universidade Estadual Paulista, Jaboticabal, 1998.

DEUBER, R. Controle de plantas daninhas na cultura da soja. In: Fundação Cargil. A soja no Brasil Central. 2 ed. Campinas, SP, p. 367-392, 1982.

DURIGAN, J.C. Efeito de adjuvantes na aplicação e eficácia dos herbicidas. Jaboticabal, FUNEP, 1993.42p.

FAWCETT, R.S. \& DAVIS, H. Effect of enviroment on glyphosate activity in quackgrass. Proc. N. Cent. Weed Contr. Conf. 31:159-160, 1976.

FERNANDEZ, C.H. Product Development Field observations. Memphis, Tenn, 1979.

JAKELAITIS, A.; FERREIRA, L. R.; SILVA, A.A.; MIRANDA, G. V. Controle de Digitaria horizontalis pelos herbicidas glifosate, sulfosate e glifosate potássico submetidos a diferentes intervalos de chuva após a aplicação. Planta Daninha, v.19, n.2, p.279-286, 2001.

KRUSE, N.D.; TREZZI, M.M.; VIDAL, R.A. Herbicidas inibidores da EPSPs: Revisão de literatura. Revista Brasileira de Herbicidas. v.1. n.2. p.139-146, 2000.

MCWHORTER, C.G. \& HANKS, J.E. Effect of spray volume and pressure on postemergence johnsongrass (sorghum halepense) control. Weed Technology. v.7. p.304-310, 1993.

PEDRINHO JUNIOR, A. F. F. Influência da chuva simulada na eficácia agronômica do herbicida glifosate, sobre diferentes formulações, concentrações e adjuvantes, no inverno e no verão. FCAV - UNESP- Jaboticabal - SP. 2001. 149p. (Trabalho de Graduação).

PEDRINHO JUNIOR, A.F.F.; MARTINI, G.; FELICI, G.V.; PIVA, F.M.; DURIGAN, J.C. Momento da chuva após a aplicação e a eficácia dos herbicidas sulfosate e glifosate aplicados em diferentes formulações. Planta Daninha, v.20, n.1, p.115-123, 2002a. 
PEDRINHO JUNIOR, A.F.F.; PIVA, F.M.; MARTINI, G.; FELICI, G.V.; DURIGAN, J.C. Influência do momento da chuva na eficácia do herbicida glifosate em mistura com adjuvantes na dessecação de plantas daninhas, no inverno e no verão. Planta Daninha, v.20, n.2, $2002 b$.

RODRIGUES, J. D. Absorção, translocação e modo de ação de defensivos (glyphosate e alachlor) Botucatu: Departamento de Fisiologia Vegetal, Faculdade de Ciências Agronômicas, UNESP, 114p. 1994. (Dissertação de Mestrado).

ROMAN, E. S. Influência de chuva simulada na eficácia de diferentes formulações e doses de glifosate. Revista Brasileira de Herbicidas, v.2, n.3, p.119-124, 2001.

SOUZA, L.C.; VALENTE, T. O.; MELHORANÇA, A. L.; PEREIRA, F. A.R.; JUNIOR, A.C. Influência de diferentes herbicidas na dessecação de três espécies vegetais para cobertura do solo. Revista Brasileira de Herbicidas, v.1, n.1, p. 57-60. 2000.

TUCKER, T.A.; LANGELAND, K.A.; CORBIN, F.T. Absorption and translocation of ${ }^{14} \mathrm{C}$ Imazapyr and ${ }^{14} \mathrm{C}$-Glyphosate in alligatorweed Alternanthera philoxeroides. Weed Technology. v.8. p.32-36, 1994. 
Tabela 01. Tratamentos com o herbicida glifosate, utilizados no inverno e no verão e os horários que foram submetidos à chuva simulada após a aplicação, para o controle de plantas daninhas, em pós-emergência, Jaboticabal SP, 2000/2001.

\begin{tabular}{|c|c|c|}
\hline Concentrações (v/v) & Dosagem (g.ha ${ }^{-1}$ de eq. ac.) & $\begin{array}{l}\text { Intervalo, em horas, } \\
\text { entre a aplicação e a } \\
\text { chuva simulada }\end{array}$ \\
\hline glifosate SAqC $^{(*)}-0,5 \%$ & 360 & $1,2,4,6 \mathrm{e}>48$ \\
\hline glifosate SAqC- $1,0 \%$ & 720 & $1,2,4,6$ e $>48$ \\
\hline glifosate SAqC- $2,0 \%$ & 1440 & $1,2,4,6$ e $>48$ \\
\hline glifosate SAqC- $4,0 \%$ & 2880 & $1,2,4,6$ e $>48$ \\
\hline Testemunha & sem herbicida & -- \\
\hline
\end{tabular}

Tabela 2: Plantas daninhas presentes com respectivos comprimento e porcentagem de cobertura da área no momento da aplicação, em cada um dos experimentos nas duas épocas do ano. Jaboticabal SP, 2000/2001.

\begin{tabular}{|c|c|c|c|c|}
\hline \multicolumn{2}{|c|}{ Épocas do ano } & Planta Daninha & Comprimento da haste & $\begin{array}{c}\% \text { de } \\
\text { cobertura }\end{array}$ \\
\hline \multirow{4}{*}{ Experimentos } & \multirow{2}{*}{ Inverno } & Alternanthera tenella Colla & $\begin{array}{l}0,4-0,45 \mathrm{~m} \text { de altura (com } \\
\text { inflorescência) }\end{array}$ & 25 \\
\hline & & $\begin{array}{l}\text { Brachiaria plantaginea } \\
\text { (Link.) Hitch. }\end{array}$ & $\begin{array}{l}0,25 \text { m de comprimento (não } \\
\text { florescida) }\end{array}$ & 65 \\
\hline & \multirow{2}{*}{ Verão } & Alternanthera tenella Colla & $\begin{array}{l}0,5 \mathrm{~m} \text { de comprimento (em pleno } \\
\text { florescimento) }\end{array}$ & 30 \\
\hline & & $\begin{array}{l}\text { Brachiaria plantaginea } \\
\text { (Link.) Hitch. }\end{array}$ & $\begin{array}{l}0,6 \text { m de comprimento (com } \\
\text { sementes) }\end{array}$ & 60 \\
\hline
\end{tabular}


Tabela 3: Dados climáticos obtidos nos respectivos horários de aplicação do herbicida, nas duas épocas do ano. Jaboticabal - SP, 2000/2001.

\begin{tabular}{|c|c|c|c|c|c|c|c|c|}
\hline \multicolumn{2}{|c|}{ Épocas do ano } & Aplicação & \multirow{2}{*}{$\begin{array}{c}\text { Horário de } \\
\text { aplicação (h) }\end{array}$} & \multirow{2}{*}{$\begin{array}{c}\text { UR } \\
\text { do } \operatorname{ar}(\%)\end{array}$} & \multirow{2}{*}{$\begin{array}{c}\mathrm{T}^{\mathrm{o}} \mathrm{C} \\
\text { Ambiente }\end{array}$} & \multirow{2}{*}{$\begin{array}{c}\mathrm{T}^{\mathrm{o}} \mathrm{C} \text { Solo } \\
(5 \mathrm{~cm})\end{array}$} & \multirow{2}{*}{$\begin{array}{l}\text { Vel. vento } \\
\text { (km/hora) }\end{array}$} & \multirow[t]{2}{*}{ Nebulosidade (\%) } \\
\hline & & Dia/mês/ano & & & & & & \\
\hline \multirow{9}{*}{ Experimentos } & \multirow{4}{*}{ Inverno } & \multirow{4}{*}{$14 / 06 / 2000$} & $08: 05-08: 20$ & 75 & 27,0 & 16,5 & Ausentes & 5 \\
\hline & & & $11: 55-12: 10$ & 42 & 33,0 & 20,8 & 5,20 & 0 \\
\hline & & & $12: 55-13: 10$ & 44 & 32,0 & 21,8 & 4,87 & 0 \\
\hline & & & $16: 30-16: 45$ & 41 & 30,0 & 22,2 & Ausentes & 5 \\
\hline & \multirow{5}{*}{ Verão } & \multirow{5}{*}{ 04/01/2001 } & $08: 20-08: 40$ & 70 & 27,0 & 23,0 & 3,0 & 70 \\
\hline & & & $10: 20-10: 40$ & 79 & 31,0 & 22,0 & 5,4 & 85 \\
\hline & & & $12: 25-12: 45$ & 65 & 33,0 & 24,0 & 3,5 & 20 \\
\hline & & & $13: 30-13: 50$ & 61 & 32,0 & 24,0 & 1,2 & 50 \\
\hline & & & $17: 30-17: 50$ & 67 & 27,0 & 23,5 & Ausentes & 70 \\
\hline
\end{tabular}


Tabela 4 - Resultados do teste F para médias das porcentagens de controle químico geral das plantas daninhas influenciado por chuvas simuladas em diferentes períodos após a aplicação de diferentes concentrações de glifosate, no inverno. Jaboticabal - SP. 2000

\begin{tabular}{|c|c|c|c|c|c|}
\hline & Fatores & & Dias & plicação & \\
\hline & & 17 & 26 & 33 & 41 \\
\hline & Testemunha x Fatores & $90,21 * *$ & $285,8 * *$ & $1666,0 * *$ & $2114,7 * *$ \\
\hline $\mathrm{F}$ & Concentrações (C) & $118,57 * *$ & $281,0 * *$ & $1072,5 * *$ & $1337,7 * *$ \\
\hline $\mathrm{F}$ & Período sem de chuva (P) & $17,99 * *$ & $58,8 * *$ & $189,2 * *$ & $250,6 * *$ \\
\hline & $\mathrm{C} \times \mathrm{P}$ & $1,56^{\mathrm{NS}}$ & $13,1 * *$ & $35,2 * *$ & $48,6 * *$ \\
\hline & $\mathrm{CV}(\%)$ & 21,6 & 12,1 & 5,0 & 4,3 \\
\hline & 0,5 & (a) $15,4 \mathrm{D}(\varepsilon$ & & & \\
\hline Concentrações (\%) & 1,0 & $38,0 \mathrm{C}$ & & & \\
\hline & 2,0 & $52,7 \mathrm{~B}(6$ & & & \\
\hline & 4,0 & $65,5 \mathrm{~A}(\varepsilon$ & & & \\
\hline dms a $5 \%$ & & 7,38 & & & \\
\hline & 1,0 & $30,5 \mathrm{C}(2$ & & & \\
\hline Períndo sem chuva & 2,0 & $40,2 \mathrm{~B}($ & & & \\
\hline Periodo sem chuva & 4,0 & $42,2 \mathrm{~B}($ & & & \\
\hline & 6,0 & $45,1 \mathrm{~B}$ & & & \\
\hline & $>48$ & $56,5 \mathrm{~A}(($ & & & \\
\hline
\end{tabular}

**significativo a $1 \%$ de probabilidade

${ }^{(a)}$ Dados transformados para a análise estatística

${ }^{(b)}$ Dados originais 
Tabela 5 - Médias das porcentagens de controle químico geral das plantas daninhas, atribuídas visualmente aos 26 DAA, no inverno, influenciado por chuvas simuladas em diferentes períodos após a aplicação de diferentes concentrações de glifosate. Desdobramento da interação (Concentração x Período sem chuvas = C x P). Jaboticabal - SP, 2000.

\begin{tabular}{|c|c|c|c|c|c|}
\hline \multirow{2}{*}{ Concentrações $(\%)^{\#}$} & \multicolumn{5}{|c|}{ Período sem chuva (h) } \\
\hline & \multirow{2}{*}{$\frac{1}{\mathrm{~d} 13,5^{*} \mathrm{~B}(5,5)^{* *}}$} & 2 & 4 & 6 & \multirow{2}{*}{$\begin{array}{c}>48 \\
\text { b } 67,1 \mathrm{~A}(82,5)\end{array}$} \\
\hline 0,5 & & c 15,4 B $\quad(7,5)$ & c 18,9 B $(13,0)$ & c 14,8 B $\quad(6,5)$ & \\
\hline 1,0 & c 26,3 C $(21,2)$ & b $31,8 \mathrm{C} \quad(28,7)$ & b 56,4 B $(68,7)$ & b 51,6 B $\quad(61,2)$ & a 81,9 A $(98,0)$ \\
\hline 2,0 & b 62,7 B $(77,5)$ & a $68,6 \mathrm{AB}(85,7)$ & a $74,3 \mathrm{AB}(92,5)$ & a $75,5 \mathrm{AB}(93,2)$ & a 81,9 A $(98,0)$ \\
\hline 4,0 & a 79,5 A $(96,5)$ & a 80,6 A $\quad(97,2)$ & a 81,9 A $\quad(98,0)$ & a 81,9 A $\quad(98,0)$ & a 81,9 A $(98,0)$ \\
\hline \multicolumn{6}{|c|}{ dms para média de períodos dentro de cada concentração = 13,16 } \\
\hline \multicolumn{6}{|c|}{ dms para médias de concentrações dentro de cada período = 12,37 } \\
\hline \multicolumn{6}{|c|}{$\begin{array}{l}\text { *Dados transformados para a análise estatística } \\
\text { **Dados originais } \\
\text { \#- Concentrações de } 0,5 ; 1,0 ; 2,0 \text { e } 4,0 \% \text { correspondem, respectivamente, as doses de } 360,720,1440 \text { e } 2880 \text { g.ha }{ }^{-1} \text { de eq. ac. de glifosate. } \\
\text { Obs: Letras minúsculas do lado esquerdo e no sentido das colunas, comparam as concentrações dentro de cada período; letras maiúsculas } \\
\text { do lado direito e no sentido das linhas, comparam os períodos dentro de cada concentração. }\end{array}$} \\
\hline \multicolumn{6}{|c|}{$\begin{array}{l}\text { Tabela 6- Médias das porcentagens de controle químico geral das plantas daninhas, atribuídas visualmente, aos } 33 \text { DAA, no inverno, } \\
\text { influenciado por chuvas simuladas em diferentes períodos após a aplicação de diferentes concentrações de glifosate. Desdobramento da } \\
\text { interação (Concentração x Período sem chuva }=\quad \mathrm{C} \text { x P). Jaboticabal - SP., } 2000 \text {. }\end{array}$} \\
\hline \multirow{2}{*}{ Concentrações $(\%)^{\#}$} & \multicolumn{5}{|c|}{ Período sem chuva (h) } \\
\hline & 1 & 2 & 4 & 6 & $>48$ \\
\hline 0,5 & $\mathrm{~d} 22,8^{*} \mathrm{C}(15,0)^{* *}$ & c 25,6 BC $(18,7)$ & d 30,6 B $\quad(26,2)$ & c 27,2 BC $(21,2)$ & c 64,4 A $(81,2)$ \\
\hline 1,0 & c $36,1 \mathrm{C} \quad(35,0)$ & b 39,8 C $\quad(41,2)$ & c 64,6 B $\quad(81,2)$ & b 61,7 B $\quad(77,5)$ & b 79,4 A $(96,5)$ \\
\hline 2,0 & b 70,4 B $(88,7)$ & a $75,7 \mathrm{AB}(93,7)$ & b 75,7 AB $(93,7)$ & a 78,3 A $(95,7)$ & b 80,6 A $(97,2)$ \\
\hline 4,0 & a 79,4 B $(96,5)$ & a 79,4 B $\quad(96,5)$ & a 81,8 B $\quad(98,0)$ & a 81,8 B $\quad(98,0)$ & a 90,0 A $(100,0)$ \\
\hline
\end{tabular}

dms para média de períodos dentro de cada concentração $=5,92$ 
*Dados transformados para a análise estatística

***Dados originais

\# - Concentrações de 0,$5 ; 1,0 ; 2,0$ e 4,0\% correspondem, respectivamente, as doses de 360, 720, 1440 e 2880 g.ha ${ }^{-1}$ de eq. ac. de glifosate.

Obs: Letras minúsculas do lado esquerdo e no sentido das colunas, comparam as concentrações dentro de cada período; letras maiúsculas do lado direito e no sentido das linhas, comparam os períodos dentro de cada concentração.

Tabela 7 - Médias das porcentagens de controle químico geral das plantas daninhas, atribuídas visualmente, aos 41 DAA, no inverno, influenciado por chuvas simuladas em diferentes períodos após a aplicação de diferentes concentrações de glifosate. Desdobramento da interação (Concentração x Período sem chuva $=$ C x P). Jaboticabal - SP, 2000.

\begin{tabular}{|c|c|c|c|c|c|}
\hline \multirow{2}{*}{ Concentrações $(\%)^{\#}$} & \multicolumn{5}{|c|}{ Período sem chuva (h) } \\
\hline & 1 & 2 & 4 & 6 & $>48$ \\
\hline 0,5 & $\mathrm{~d} 22,8^{*} \mathrm{C}(15,0)^{* *}$ & d 26,5 BC $(20,0)$ & d 31,5 B $(27,5)$ & c 30,0 B $\quad(25,0)$ & c 68,3 A $(86,2)$ \\
\hline 1,0 & c $36,9 \mathrm{C} \quad(36,2)$ & c 41,3 C $\quad(43,7)$ & c $64,6 \mathrm{~B}(81,2)$ & b 61,7 B $\quad(77,5)$ & b 79,4 A $(96,5)$ \\
\hline 2,0 & b 70,4 C $(88,7)$ & b 75,7 B & b 75,7 B $(93,7)$ & a $78,2 \mathrm{AB}(95,7)$ & a 81,8 A $(98,0)$ \\
\hline 4,0 & a 81,8 B $(98,0)$ & a $81,8 \mathrm{~B}$ & a 81,8 B $(98,0)$ & a $81,8 \mathrm{~B}$ & a 90,0 A $(100,0)$ \\
\hline
\end{tabular}

dms para média de períodos dentro de cada concentração $=5,21$

dms para médias de concentrações dentro de cada período $=4,89$

*Dados transformados para a análise estatística

**Dados originais

\# - Concentrações de 0,5; 1,0; 2,0 e 4,0\% correspondem, respectivamente, as doses de 360, 720, 1440 e 2880 g.ha ${ }^{-1}$ de eq. ac. de glifosate.

Obs: Letras minúsculas do lado esquerdo e no sentido das colunas, comparam as concentrações dentro de cada período; letras maiúsculas do lado direito e no sentido das linhas, comparam os períodos dentro de cada concentração. 
Tabela 8 - Resultados do teste F para médias das porcentagens de controle químico geral das plantas daninhas influenciado por chuvas simuladas em diferentes períodos após a aplicação de diferentes concentrações de glifosate, no verão. Jaboticabal - SP. 2001

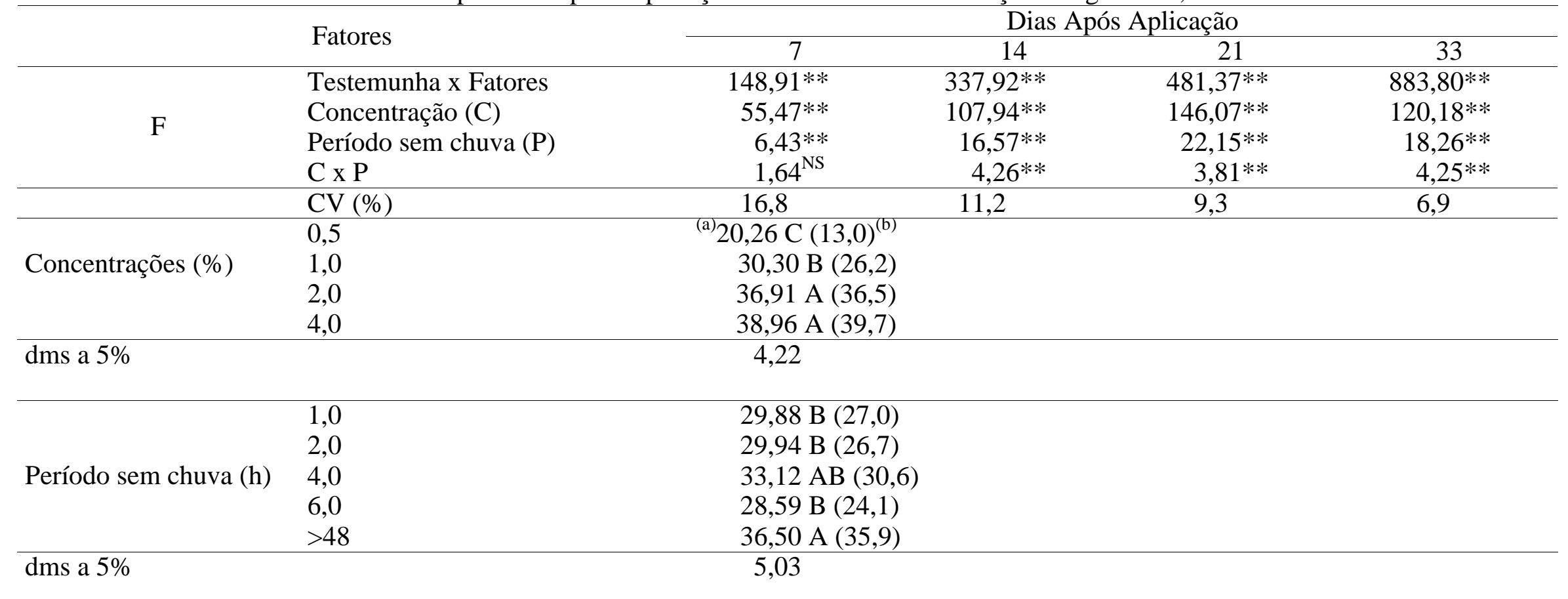

\footnotetext{
**significativo a $1 \%$ de probabilidade

(a) Dados transformados para a análise estatística

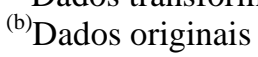


Tabela 9 - Médias das porcentagens de controle químico geral das plantas daninhas, atribuídas visualmente aos 14 DAA, no inverno, influenciado por chuvas simuladas em diferentes períodos após a aplicação de diferentes concentrações de glifosate. Desdobramento da interação (Concentração x Período sem chuva = C x P). Jaboticabal - SP, 2001.

\begin{tabular}{|c|c|c|c|c|c|}
\hline \multirow{2}{*}{ Concentrações $(\%)^{\#}$} & \multicolumn{5}{|c|}{ Período sem chuva (h) } \\
\hline & 1 & 2 & 4 & 6 & $>48$ \\
\hline 0,5 & c $21,1 * \mathrm{C}(13,7)^{* *}$ & b 39,1 B $\quad(40,0)$ & c 45,0 B $\quad(50,0)$ & c $36,1 \mathrm{~B} \quad(35,0)$ & b $61,4 \mathrm{~A}(76,2)$ \\
\hline 1,0 & b $56,3 \mathrm{AB}(68,7)$ & b 47,9 B $\quad(55,0)$ & b $60,1 \mathrm{AB}(75,0)$ & b 52,2 B $(62,5)$ & ab $66,4 \mathrm{~A}(83,7)$ \\
\hline 2,0 & b 61,3 B $(75,0)$ & a $67,3 \mathrm{AB}(85,0)$ & ab 68,3 AB $(86,2)$ & a $64,7 \mathrm{AB}(81,2)$ & a 75,5 A $(93,7)$ \\
\hline 4,0 & a $75,0 \mathrm{~A} \quad(93,7)$ & a $73,2 \mathrm{~A} \quad(91,2)$ & a 73,2 A $(91,2)$ & a $72,9 \mathrm{~A} \quad(91,2)$ & a $77,0 \mathrm{~A}(95,0)$ \\
\hline
\end{tabular}

dms para média de períodos dentro de cada concentração $=12,63$

dms para médias de concentrações dentro de cada período $=11,86$

*Dados transformados para a análise estatística

**Dados originais

\# - Concentrações de 0,5; 1,0; 2,0 e 4,0\% correspondem, respectivamente, as doses de 360, 720, 1440 e 2880 g.ha ${ }^{-1}$ de eq. ac. de glifosate.

Obs: Letras minúsculas do lado esquerdo e no sentido das colunas, comparam as concentrações dentro de cada período; letras maiúsculas do lado direito e no sentido das linhas, comparam os períodos dentro de cada concentração. 
Tabela 10 - Médias das porcentagens de controle químico geral das plantas daninhas, atribuídas visualmente, aos 21 DAA, no verão, influenciado por chuvas simuladas em diferentes períodos após a aplicação de diferentes concentrações de glifosate. Desdobramento da interação (Concentração x Período sem chuva = C x P). Jaboticabal - SP., 2001.

\begin{tabular}{|c|c|c|c|c|c|}
\hline \multirow{2}{*}{ Concentrações $(\%)^{\#}$} & \multicolumn{5}{|c|}{ Período livre de chuvas } \\
\hline & 1 & 2 & 4 & 6 & $>48$ \\
\hline 0,5 & c $26,9 * \mathrm{C}(21,2)^{* *}$ & c $42,1 \mathrm{~B}(45,0)$ & c $53,8 \mathrm{AB}(65,0)$ & c 44,2 B $\quad(48,7)$ & c 64,7 A $(81,2)$ \\
\hline 1,0 & b $63,5 \mathrm{BC}(78,7)$ & b 56,6 C $(68,7)$ & b 69,3 AB $(87,5)$ & b $60,1 \mathrm{BC}(75,0)$ & bc 75,7 A $(93,7)$ \\
\hline 2,0 & b 69,8 B & a 72,8 B $(91,7)$ & ab 73,9 B $\quad(91,7)$ & a 73,5 B $\quad(91,5)$ & ab 86,0 A $(99,0)$ \\
\hline 4,0 & a $84,0 \mathrm{~A}$ & a $83,4 \mathrm{~A}(98,5)$ & a $82,2 \mathrm{~A} \quad(98,0)$ & a $82,1 \mathrm{~A}$ & a 90,0 A $(100,0)$ \\
\hline
\end{tabular}

dms para média de períodos dentro de cada concentração $=11,99$

dms para médias de concentrações dentro de cada período $=11,27$

*Dados transformados para a análise estatística

**Dados originais

\# - Concentrações de 0,$5 ; 1,0 ; 2,0$ e 4,0\% correspondem, respectivamente, as doses de 360, 720, 1440 e 2880 g.ha ${ }^{-1}$ de eq. ac. de glifosate.

Obs: Letras minúsculas do lado esquerdo e no sentido das colunas, comparam as concentrações dentro de cada período; letras maiúsculas do lado

direito e no sentido das linhas, comparam os períodos dentro de cada concentração. 
Tabela 11 - Médias das porcentagens de controle químico geral das plantas daninhas, atribuídas visualmente, aos 33 DAA, no verão, influenciado por chuvas simuladas em diferentes períodos após a aplicação de diferentes concentrações de glifosate. Desdobramento da interação (Concentração x Período sem chuva = C x P). Jaboticabal - SP, 2001.

\begin{tabular}{|c|c|c|c|c|c|}
\hline \multirow{2}{*}{ Concentrações $(\%)^{\#}$} & \multicolumn{5}{|c|}{ Período sem chuva (h) } \\
\hline & 1 & 2 & 4 & 6 & $>48$ \\
\hline 0,5 & c $47,1 * \mathrm{D}(53,7)^{* *}$ & c $53,1 \mathrm{CD}(63,7)$ & c 63,4 B $(80,0)$ & c $58,1 \mathrm{CD}(71,2)$ & b 77,6 A $(93,2)$ \\
\hline 1,0 & b 74,4 B $\quad(92,0)$ & b 71,8 B $\quad(88,2)$ & b 72,9 B $(91,2)$ & b 69,3 B $\quad(87,5)$ & ab 85,9 A $(99,0)$ \\
\hline 2,0 & ab 81,2 A $(97,5)$ & a $82,4 \mathrm{~A} \quad(98,2)$ & ab 81,8 A $(98,0)$ & a 80,2 A $(97,0)$ & a 90,0 A $(100,0)$ \\
\hline 4,0 & a $90,0 \mathrm{~A} \quad(100,0)$ & a 87,9 A $(99,5)$ & a 85,4 A $(98,7)$ & a 86,5 A $(99,2)$ & a 90,0 A $(100,0)$ \\
\hline
\end{tabular}

dms para média de períodos dentro de cada concentração $=9,99$

dms para médias de concentrações dentro de cada período $=9,39$

*Dados transformados para a análise estatística

**Dados originais

\# - Concentrações de 0,$5 ; 1,0 ; 2,0$ e 4,0\% correspondem, respectivamente, as doses de 360, 720, 1440 e 2880 g.ha ${ }^{-1}$ de eq. ac. de glifosate.

Obs: Letras minúsculas do lado esquerdo e no sentido das colunas, comparam as concentrações dentro de cada período; letras maiúsculas do lado direito e no sentido das linhas, comparam os períodos dentro de cada concentração. 
Tabela 12 - Médias das massas "in natura" e seca, aos 41 (inverno) e 33 (verão) DAA, influenciadas por chuvas simuladas em diferentes períodos após a aplicação de concentrações do glifosate. Jaboticabal - SP, 2000./ 2001.

\begin{tabular}{|c|c|c|c|c|c|}
\hline \multirow{2}{*}{\multicolumn{2}{|c|}{ Fatores }} & \multicolumn{2}{|c|}{ Inverno } & \multicolumn{2}{|c|}{ Verão } \\
\hline & & in natura $(\mathrm{kg})$ & seca $(\mathrm{kg})$ & in natura $(\mathrm{kg})$ & seca $(\mathrm{kg})$ \\
\hline \multirow{4}{*}{$\mathrm{F}$} & Testemunha x Fator & $252,12 * *$ & $49,07 * *$ & $327,12 * *$ & $33,64 * *$ \\
\hline & Concentrações (C) & $36,86 * *$ & $14,59 * *$ & $11,39 * *$ & $0,50^{\mathrm{ns}}$ \\
\hline & Período livre de Chuva (P) & $8,72 * *$ & $2,21^{\mathrm{NS}}$ & $1,42^{\mathrm{NS}}$ & $0,28^{\mathrm{ns}}$ \\
\hline & $\mathrm{C} \times \mathrm{P}$ & $1,81^{\mathrm{NS}}$ & $0,93^{\mathrm{NS}}$ & $1,08^{\mathrm{NS}}$ & $1,65^{\mathrm{ns}}$ \\
\hline $\mathrm{CV}(\%)$ & & 41,4 & 43,7 & 58,7 & 83,8 \\
\hline \multirow{4}{*}{ Concentrações $(\%)^{\#}$} & 0,5 & $0,72 \mathrm{~A}$ & $0,18 \mathrm{~A}$ & $0,41^{\mathrm{A}}$ & $0,14 \mathrm{~A}$ \\
\hline & 1,0 & $0,37 \mathrm{~B}$ & $0,12 \mathrm{~B}$ & $0,26 \mathrm{AB}$ & $0,19 \mathrm{~A}$ \\
\hline & 2,0 & $0,29 \mathrm{~B}$ & $0,12 \mathrm{~B}$ & $0,11 \mathrm{C}$ & $0,17 \mathrm{~A}$ \\
\hline & 4,0 & $0,12 \mathrm{C}$ & $0,06 \mathrm{C}$ & $0,14 \mathrm{BC}$ & $0,15 \mathrm{~A}$ \\
\hline dms a $5 \%$ & & 0,15 & 0,04 & 0,15 & 0,13 \\
\hline \multirow{5}{*}{ Períodos sem chuva (h) } & 1 & $0,48 \mathrm{~A}$ & $0,14 \mathrm{~A}$ & $0,26 \mathrm{~A}$ & $0,16 \mathrm{~A}$ \\
\hline & 2 & $0,50 \mathrm{~A}$ & $0,14 \mathrm{~A}$ & $0,26 \mathrm{~A}$ & $0,15 \mathrm{~A}$ \\
\hline & 4 & $0,35 \mathrm{~A}$ & $0,11 \mathrm{~A}$ & $0,16 \mathrm{~A}$ & $0,20 \mathrm{~A}$ \\
\hline & 6 & $0,37 \mathrm{~A}$ & $0,12 \mathrm{~A}$ & $0,28 \mathrm{~A}$ & $0,14 \mathrm{~A}$ \\
\hline & $>48$ & $0,16 \mathrm{~B}$ & $0,09 \mathrm{~A}$ & $0,18 \mathrm{~A}$ & $0,15 \mathrm{~A}$ \\
\hline dms a $5 \%$ & & 0,18 & 0,06 & 0,18 & 0,06 \\
\hline
\end{tabular}

**significativo a $1 \%$ de probabilidade

\# - Concentrações de 0,$5 ; 1,0 ; 2,0$ e 4,0\% correspondem, respectivamente, as doses de $360,720,1440$ e 2880 g.ha ${ }^{-1}$ de eq. ac. de glifosate. 